\title{
Appropriateness of hospital admissions in general hospitals in Egypt
}

M. Al-Tehewy, ${ }^{1}$ E. Shehad, ${ }^{1}$ M. Al Gaafary, ${ }^{1}$ M. Al-Houssiny, ${ }^{1}$ D. Nabih ${ }^{1}$ and B. Salem ${ }^{2}$

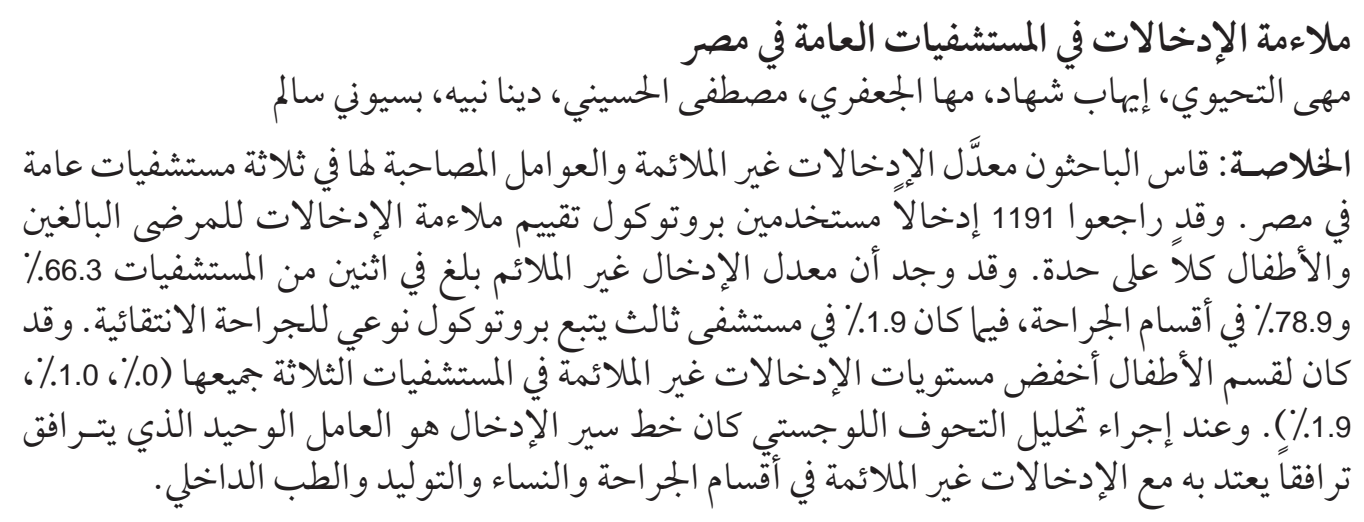

ABSTRACT We measured the rate of inappropriate admissions, and associated factors, in 3 general hospitals in Egypt. A total of 1191 admissions were reviewed using the Appropriateness Evaluation Protocol for adult patients and the Pediatric Appropriateness Evaluation Protocol for paediatric patients. Inappropriate admissions were $66.3 \%$ and $78.9 \%$ of admissions in the surgery departments of 2 hospitals compared with $1.9 \%$ in the 3rd hospital that followed a specific admission protocol for elective surgery. The paediatrics department had the lowest rates of inappropriate admissions in all hospitals $(0 \%, 1.0 \%$ and $1.9 \%)$. On logistic regression analysis, the route of admission was the only factor significantly associated with inappropriate admissions in the departments of surgery, obstetrics/gynaecology and internal medicine.

\section{Adéquation des admissions dans les hôpitaux généraux en Égypte}

RÉSUMÉ Nous avons mesuré le taux d'admissions non pertinentes dans trois hôpitaux généraux en Égypte, ainsi que les facteurs associés. Au total, 1191 admissions ont été analysées à l'aide du protocole d'évaluation Appropriateness Evaluation Protocol pour les patients adultes et du protocole Pediatric Appropriateness Evaluation Protocol pour les patients pédiatriques. Les admissions non pertinentes représentaient $66,3 \%$ et $78,9 \%$ des admissions dans les services de chirurgie de deux hôpitaux, contre 1,9 \% dans le troisième hôpital qui suivait un protocole d'hospitalisation spécial pour la chirurgie réglée. Dans tous les hôpitaux, les services de pédiatrie enregistraient les taux d'admissions non pertinentes les plus faibles ( $0 \%, 1,0 \%$ et 1,9\%). Dans l'analyse de régression logistique, le mode d'admission était le seul facteur significativement associé aux admissions non pertinentes dans les services de chirurgie, de gynécologie-obstétrique et de médecine interne.

\footnotetext{
${ }^{1}$ Health Care Quality Unit, Ain Shams University, Cairo, Egypt (Correspondence to M.Al-Tehewy: al_tehewy@ yahoo.com).

${ }^{2}$ General Directorate of Quality, Ministry of Health, Cairo, Egypt.

Received: 18/11/06; accepted: 10/05/07
} 


\section{Introduction}

Controlling health expenditure is a key element of health care management. With advances in new medical technologies the costs of health care are rising constantly worldwide, and cost containment is major topic of research and applied policies. Utilization review is the backbone of such research and policy-making [1].

One aspect of the utilization review process is assessing the appropriateness of hospitalization, from the appropriateness of admission through to the appropriate length of stay. Besides the unnecessary increase in cost, inappropriate hospitalization leads to an unnecessarily high bed occupancy rate and has been linked to poor quality of care due to hospital overload [2]. Accordingly, applying health care interventions to eliminate unnecessary hospitalization reduces health care expenditure, improves the quality of care for patients and increases the accessibility to care for patients on waiting lists [3]. The Appropriateness Evaluation Protocol (AEP) is the tool most commonly used to assess the appropriateness of admission and days of care in hospitals [4].

The current study aimed to measure the rate of inappropriate admissions to 3 general hospitals in Egypt and the characteristics associated with the inappropriateness.

\section{Methods}

\section{Study setting}

The study compared the appropriateness of admissions in 3 general government hospitals located in 3 different governorates of Egypt: Cairo, Giza and Alexandria. The hospital in Alexandria had an admission protocol for doing all diagnostic or preoperative investigations for elective operations on an outpatient basis, while the other 2 hospitals had no admission protocol to follow. The 3 selected hospitals were similar regarding the bed capacity: 150-200 beds. Besides patients admitted for free services, general hospitals in Egypt usually accept patients with paid services and with insurance coverage. The medical care delivered is the same but the services are delivered in different departments. All admitted cases in the 3 hospitals were eligible for inclusion in the study.

\section{Sample}

The sample size was estimated to be 200 patients per hospital according to a percentage of inappropriatene admissions of $15 \%$ [5] $\pm 5 \%$ degree of precision at the $95 \%$ confidence interval. The sample size was doubled for each hospital in order to allow a sufficiently large sample for cross-tabulation and for calculating the percentage of inappropriate addmisssions in different categories. Accordingly, 400 consecutive admissions were concurrently reviewed from each hospital until the sample size was achieved. The study was carried out over the year 2004.

\section{Data collection}

A data collection sheet was designed to record information from the patients' records about each case admitted: the patient's personal data, time of admission, day of admission, payment method, reason for admission, laboratory findings at the time of admission, provisional diagnosis and management plan. In each hospital 4 physicians, 1 in each of the main departments (surgery, obstetrics/gynaecology, internal medicine and paediatrics), were trained to fill the data sheet.

Two reviewers independently reviewed the sheets and evaluated the appropriateness of admissions using the AEP [6] and the Pediatric Appropriateness Evaluation Protocol for Paediatric patients (PAEP) [7]. The AEP consists of a set of explicit criteria that indicate the need for acute hospital care

المجلة الصحية لشرق المتوسط، منظمة الصحة العالمية، المجلد الخامس عشر، العدد 0،9 +.ب 
on the basis of the patient's condition and the services delivered to the patient. It has several strengths: it has been extensively tested for reliability and validity and it is generic rather than diagnosis- or procedurespecific. The AEP rates the appropriateness of hospital admission using 17 criteria for the clinical stability of the patient, necessity of medical interventions and planned surgical procedures within 24 hours. An admission is considered appropriate if 1 or more of these criteria are satisfied. The PAEP is a modification of the AEP to be applied in paediatric settings.

Data were analysed using SPSS, version 12. Descriptive analysis was done to calculate proportions and reasons for inappropriate admissions in different departments. All independent factors considered risk factors for inappropriate admissions were adjusted for hospital across the different departments using logistic regression. Adjusted odds ratio (OR) and 95\% confidence interval (CI) were computed for each factor.

\section{Results}

A total of 1191 admissions were reviewed from the 4 main departments of the studied hospitals. As shown in Table 1, the rates of inappropriate admissions were highest in the department of surgery in hospital A (in Cairo) and B (in Giza) (78.8\% and 66.3\% respectively). The department of obstetrics/gynaecology had the next highest with $20.7 \%$ inappropriate admissions in hospital A and 58.4\% in hospital B. Hospital C (in Alexandria) had an extremely low rate of inappropriate admissions in the departments of surgery and obstetrics/gynaecology $(1.9 \%$ and $1.0 \%)$. The department of internal medicine showed similar rates of inappropriate admissions in the 3 hospitals (17.4\%, $17.0 \%$ and $21.3 \%)$. The department of paediatrics had the lowest inappropriate admissions in the 3 hospitals $(0.0 \%, 1.0 \%$ and $1.9 \%$ ). With such low rates, the department of paediatrics was withdrawn from further analysis.

Diagnostic and preoperative investigations were the main reason for inappropriate admissions in all departments in the 3 hospitals (Table 2).

To determine the factors related to inappropriate admissions, the following factors were adjusted for the significant effect of the hospital using multiple logistic regression: age, sex, social status, education level, day

\begin{tabular}{|c|c|c|c|c|c|c|c|c|c|c|}
\hline \multirow[t]{3}{*}{ Department } & \multicolumn{3}{|c|}{ Hospital A (Cairo) } & \multicolumn{3}{|c|}{ Hospital B (Giza) } & \multicolumn{3}{|c|}{$\begin{array}{l}\text { Hospital C } \\
\text { (Alexandria) }\end{array}$} & \multirow[t]{3}{*}{$P$-value } \\
\hline & \multirow{2}{*}{$\begin{array}{l}\text { Total } \\
\text { No. }\end{array}$} & \multicolumn{2}{|c|}{$\begin{array}{l}\text { Inappropriate } \\
\text { admissions }\end{array}$} & \multirow{2}{*}{$\begin{array}{l}\text { Total } \\
\text { No. }\end{array}$} & \multicolumn{2}{|c|}{$\begin{array}{l}\text { Inappropriate } \\
\text { admissions }\end{array}$} & \multirow{2}{*}{$\begin{array}{l}\text { Total } \\
\text { No. }\end{array}$} & \multicolumn{2}{|c|}{$\begin{array}{c}\text { Inappropriate } \\
\text { admissions }\end{array}$} & \\
\hline & & No. & $\%$ & & No. & $\%$ & & No. & $\%$ & \\
\hline Surgery & 157 & 123 & 78.8 & 162 & 106 & 66.3 & 103 & 2 & 1.9 & $<0.001$ \\
\hline \multicolumn{11}{|l|}{ Obstetrics \& } \\
\hline gynaecology & 116 & 24 & 20.7 & 77 & 45 & 58.4 & 102 & 1 & 1.0 & $<0.001$ \\
\hline Internal medicine & 92 & 16 & 17.4 & 47 & 8 & 17.0 & 89 & 19 & 21.3 & 0.743 \\
\hline Paediatrics & 41 & 0 & 0.0 & 102 & 1 & 1.0 & 103 & 2 & 1.9 & 0.609 \\
\hline Total & 406 & 163 & 40.1 & 388 & 160 & 41.2 & 397 & 24 & 6.0 & \\
\hline
\end{tabular}


Table 2 Reasons for inappropriate admissions as a proportion of inappropriate admissions by study hospital and department

\begin{tabular}{|c|c|c|c|c|c|c|}
\hline \multirow{3}{*}{$\begin{array}{l}\text { Department/reason for } \\
\text { admission }\end{array}$} & \multicolumn{6}{|c|}{ Inappropriate admissions to: } \\
\hline & \multicolumn{2}{|c|}{$\begin{array}{l}\text { Hospital A } \\
\text { (Cairo) }\end{array}$} & \multicolumn{2}{|c|}{$\begin{array}{l}\text { Hospital B } \\
\text { (Giza) }\end{array}$} & \multicolumn{2}{|c|}{$\begin{array}{l}\text { Hospital C } \\
\text { (Alexandria) }\end{array}$} \\
\hline & No. & $\%$ & No. & $\%$ & No. & $\%$ \\
\hline \multicolumn{7}{|l|}{ Surgery } \\
\hline $\begin{array}{l}\text { Diagnostic/preoperative } \\
\text { investigation }\end{array}$ & 80 & 65.0 & 96 & 90.6 & 0 & 0.0 \\
\hline Awaiting operation & 43 & 35.0 & 8 & 7.5 & 0 & 0.0 \\
\hline Other & 0 & 0.0 & 2 & 3.6 & 2 & 100.0 \\
\hline \multicolumn{7}{|l|}{ Obstetrics \& gynaecology } \\
\hline $\begin{array}{l}\text { Diagnostic/preoperative } \\
\text { investigation }\end{array}$ & 20 & 83.3 & 43 & 95.6 & 0 & 0.0 \\
\hline Awaiting operation & 0 & 0.0 & 1 & 2.2 & 0 & 0.0 \\
\hline Other & 4 & 16.7 & 1 & 2.2 & 1 & 100.0 \\
\hline \multicolumn{7}{|l|}{ Internal medicine } \\
\hline Diagnostic investigation & 15 & 93.8 & 8 & 100.0 & 18 & 94.8 \\
\hline Other & 1 & 6.3 & 0 & 0.0 & 1 & 5.3 \\
\hline \multicolumn{7}{|l|}{ Paediatrics } \\
\hline Diagnostic investigation & 0 & 0.0 & 1 & 100.0 & 1 & 50.0 \\
\hline Other & 0 & 0.0 & 0 & 0.0 & 1 & 50.0 \\
\hline
\end{tabular}

of admission, route of admission and payment method. For the surgery, obstetrics/ gynaecology and internal medicine departments, the route of admission was the only factor significantly associated with inappropriate admissions $(P<0.05)$ (Table 3$)$.

\section{Discussion}

The present study assessed the appropriateness of admissions using the AEP in the departments of surgery, obstetrics/gynaecology and internal medicine and using the PAEP in the department of paediatrics. Although the AEP has been modified in some countries to cope with the specific characteristics of each country, it is easily interpreted and has a good reliability and validity, leading to its continued use across different countries [8].
The appropriateness of admission in the paediatrics departments in the 3 study hospitals did not exceed $2 \%$ using the PAEP auditing tool, compared with an average $11 \%-25 \%$ in most countries [9]. Formby et al. evaluated the medical records of paediatric patients in Australia and found 24\% of admissions were inappropriate [10]. In Canada, Smith et al. examined admissions to acute wards in a tertiary care paediatric facility and found $29 \%$ of the admissions unnecessary [11]. This suggests either that there is a lack of standardized case management, with a tendency towards intensive treatments requiring admission even though patients may not be in need of such treatments (e.g. using intravenous rehydration therapy to manage mild/moderate dehydration) or else that the tool itself needs to be modified for Egyptian clinical practice. 
This was considered the most important limitation in this study. Unless hospitals use standardized case management for the common diseases in paediatrics, application of the PAEP for admissions review will be limited.

The 3 study hospitals were general hospitals with similar bed capacities, representing the main hospital provision in Egypt. The highest rate for inappropriate admissions was found in the departments of surgery followed by the department of obstetrics/gynaecology, ranging from $20.7 \%$ to $78.8 \%$ in hospitals $\mathrm{A}$ and $\mathrm{B}$. The main reason for inappropriate admissions to these hospitals was undergoing the necessary diagnostic or preoperative investigations in an inpatient rather than an outpatient setting. This explains the very low rate of inappropriate admissions in hospital $\mathrm{C}$, which applies a policy of doing investigations for elective surgery in the outpatient setting. As the policy in the Alexandria hospital was concerned with elective operations, this discrepancy was not observed in the department of internal medicine where the 3 hospitals had comparable rates of inappropriate admissions, ranging from $17.0 \%$ to $21.3 \%$, with diagnostic investigations being the main reason for inappropriate hospitalization.

The percentage of inappropriate admissions to the surgery departments in hospitals $\mathrm{A}$ and $\mathrm{B}$ was higher than that reported in other countries. Teke et al. found inappropriate admissions to be $21 \%$ of total admissions in the surgery department of a Turkish hospital [12]. Other studies have reported rates of inappropriate admissions ranging from $16 \%$ to $33 \%[13,14]$. In the department of internal medicine, inappropriate admissions in the 3 hospitals were comparable to studies in many countries. In Spain, Luis et al. found inappropriate admissions to the internal medicine department to be $17 \%$
[15] and in another study it was $13 \%$ [16]. In Switzerland, inappropriate admissions were reported to be $15 \%$ [5].

The main reason for avoidable admissions in the current study was doing diagnostic or preoperative investigations after admission, a finding that agrees with a number of other studies [17-20].

Using logistic regression to adjust for the hospital, admission through the outpatient clinic compared to emergency admission was the sole independent factor related to inappropriate admission in the departments of surgery, obstetrics/gynaecology and internal medicine. The proportion of inappropriate admissions ranged from $1.2 \%$ to $8.0 \%$ among cases admitted through the emergency room compared with $30.0 \%-$ $68.9 \%$ among patients admitted through outpatient clinics. This implies that system factors within the hospital are the main contributor to inappropriate admissions and that patient-related factors such as age or sex were not associated with inappropriate hospitalization. Accordingly, efforts to review and improve the system of admission, possibly through review and related policies, will greatly affect the utilization of hospital bed capacity.

The route of admission, whether through the emergency room or outpatient clinic, plays a main contributing factor in the analysis of inappropriate admissions. Some studies reported inappropriate admissions among urgent cases to be $23 \%-28 \%$ $[21,22]$. Other studies showed lower rates of inappropriateness of $4 \%-5 \%$ [23-25]. Although the rate of inappropriatene admission among emergencies may vary from one hospital to another and from one country to another, it is the difference between the rate of inappropriate admissions between patients admitted through the emergency room or through the outpatient clinics that has to be identified as the determin-

المجلة الصحية لشرق المتوسط، منظمة الصحة العالمية، المجلد الخامس عشر، العدد 0، 9.ب 
ing factor in inappropriateness. Navarro et al. mentioned that scheduled admission had an odds ratio of inappropriateness 15 times that of unscheduled admission [26]. A similar result was noted by Angelillo et al., where planned admission was a significant predictor of inappropriate admission [25]. Fernandez et al. in a study on appropriateness of admissions to an ear, nose and throat department reported a percentage of inappropriateness of $6 \%$ among patients undergoing elective surgery compared with $0 \%$ among non-elective admissions [27].

In view of concerns about the burden of unjustified hospitalizations on health budgets, efforts have focused on interventions to reduce inappropriate admissions and hospital days. This has been approached using pre-set criteria for hospitalization [28], redesigning the processes using quality improvement projects [29] and utilization review programmes [30]. Along with confirmed improvement in usage of hospital beds in these studies, the current study showed that the percentage of appropriate admissions in the Alexandria hospital was high as it applied a protocol that specified doing necessary investigations in the surgery and obstetrics departments before the admission in an outpatient setting. With the rapid evolution of third-party payers in most countries, including developing countries, it seems imperative to focus on research that supports decisions and proper interventions for better hospital utilization.

\section{Acknowledgements}

This work was funded by Special Grant for Research in Priority Areas of Public Health offered by the World Health Organization Regional Office for the Eastern Mediterranean. We acknowledge the great support of all the staff members of the Research Policy and Cooperation Unit, especially Dr M. Abur Rab who was very generous in advice and support. Especial appreciation should be given to directors and administration staff of the 3 hospitals for facilitating the conduct of the work and thanks are also given to every person who cooperated with the research team.

\section{References}

1. Rosenstein AH. Health economics and resource management: a model for hospital efficiency. Hospital and health services administration, 1991, 36(3):314-29.

2. Hartz AJ et al. Hospital characteristics and mortality rates. New England journal of medicine, 1989, 321(25):1720-5.

3. Brennan TA et al. Incidence of adverse events and negligence in hospitalized patients. Results of the Harvard Medical Practice Study I. New England journal of medicine, 1991, 324(6):370-6.

4. Strumwasser IRA et al. Reliability and validity of utilization review criteria: appropriateness Evaluation protocol. Medical care, 1990, 28 (2):95-109.
5. Perneger TV et al. Risk factors for a medically inappropriate admission to a department of internal medicine. Archives of internal medicine, 1997, 157(13):1495-500.

6. Gertman PM, Restuccia JD. The appropriateness evaluation protocol: a technique for assessing unnecessary days of hospital care. Medical care, 1981, 19(8):855-71.

7. Kreger BE, Restuccia JD. Assessing the need to hospitalize children: pediatric appropriateness evaluation protocol. Pediatrics, 1989, 84:242-7.

8. Tsang P, Severs MP. A study of appropriateness of acute geriatric admissions and 
an assessment of the Appropriateness Evaluation Protocol. Journal of the Royal College of Physicians of London, 1995, 29(4):311-14.

9. McDonagh MS et al. Measuring appropriate use of acute beds. A systematic review of methods and results. Health policy, 2000, 53(3):157-84.

10. Formby DJ et al. The appropriateness evaluation protocol: application in an Australian children's hospital. Australian clinical review, 1991, 11(4):123-31.

11. Smith HE et al. Assessing the utilization of in-patient facilities in a Canadian pediatric hospital. Pediatrics, 1993, 92(4):587-93.

12. Teke $\mathrm{K}$ et al. Appropriateness of admission and length of stay in a Turkish Military Hospital. Journal of medical systems, 2004, 28(6):653-63.

13. Lombardi $A$ et al. Uso appropriato della strutturaospedalierainchirurgiad'urgenza: applicazione dell'Appropriateness Evaluation Protocol [Appropriate hospital utilization in emergency surgery: application of the Appropriateness Evaluation Protocol]. Giornale di chirurgia, 2000, 21(10):36972.

14. Sangha $O$ et al. Metric properties of the appropriateness evaluation protocol and predictors of inappropriate hospital use in Germany: an approach using longitudinal patient data. International journal for quality in health care, 2002, 4(6):483-92.

15. Luis Zambrana Garcia J et al. Factores predictivos de estancias no adecuadas en un servicio de medicina interna [Predictive factors for inappropriate hospital stays in an internal medicine department]. Medicina clinica, 2001, 117(3):90-2.

16. Rodríguez-Vera FJ et al. Adecuacion de los ingresos en un servicio de Medicina Interna de un hospital de segundo nivel [Appropriateness of admissions to an internal medicine department of a second level hospital]. Anales de medicina interna, 1999, 16(6):277-80.
17. Capalbo $G$ et al. Applicazione dello strumento PRUO per la valutazione di appropriatezza dei ricoveri brevi: l'esperienza di un Policlinico Universitario [Appropriateness evaluation of short hospital admissions using Appropriateness. Evaluation Protocol (Italian version): experience of a teaching hospital]. Annali di igiene, 2004, 16(6):759-65.

18. Kaya $S$ et al. Factors affecting appropriateness of hospital utilization in two hospitals in Turkey. Journal of medical systems, 2001, 25(6):373-83.

19. Attena $F$ et al. Appropriateness of admission and hospitalization days in a specialist hospital. Annali di igiene, 2001, 13(2):121-7.

20. Mirón Canelo JA et al. Estimacion de ingresos y estancias inadecuadas en un hospital comarcal [Admissions estimate and inadequate stays in a regional hospital]. Revista clínica española, 2000, 200(12):654-8.

21. Pileggi $C$ et al. Inappropriate hospital use by patients needing urgent medical attention in Italy. Public health, 2004, 118(4):284-91.

22. Thollander $\mathrm{J}$ et al. Att bedoma inadekvata medicinska akutinlaggningar. En studie av 566 konsekutiva fall [Assessment of inappropriate emergency admissions. A study of 566 consecutive cases]. Lakartidningen, 2004, 101(10):888-92.

23. Ochoa-Gomez $\mathrm{J}$ et al. Adecuacion de los ingresos hospitalarios urgentes [Appropriateness of emergency hospital admissions]. Anales de medicina interna, 2002, 19(9):446-8.

24. Tomás Vecina S et al. Evaluacion del uso apropiado de un area de observacion de urgencias mediante el Appropriateness Evaluation Protocol: un analisis de 4700 casos [Assessment of the appropriate utilization of an emergency department observation unit with the Appropriateness 
Evaluation Protocol: analysis of 4700 cases]. Anales de medicina interna, 2000, 17(5):229-37.

25. Angelillo IF et al. Appropriateness of hospital utilisation in Italy. Public health, 2000, 114(1):9-14.

26. Navarro G et al. Review of the utilisation of a university hospital in Barcelona (Spain): evolution 1992-1996. European journal of epidemiology, 2001, 17(7):679-84.

27. Fernández Martin $\mathrm{J}$ et al. Adecuacion de los ingresos y dias de estancia en un servicio de otorrinolaringologia [Appropriateness of admissions and duration of stay in an ear, nose and throat depart- ment]. Acta otorrinolaringologica espanola, 1997, 48(2):139-45.

28. Vardi A et al. A controlled intervention in reduction of redundant hospital days. International journal of epidemiology, 1996, 25(3):604-8.

29. Kossovsky MP et al. Evaluation of quality improvement interventions to reduce inappropriate hospital use. International journal for quality in health care, 2002, 14(3):227-32.

30. Cardiff $\mathrm{K}$ et al. Evaluation of a hospitalbased utilization management program. Healthcare management forum, 1995, 8(1):38-45.

Fifty-sixth Session of the Regional Committee for the Eastern Mediterranean

The Fifty-sixth Session of the Regional Committee for the Eastern Mediterranean is scheduled to take place in Fez, Morocco, from Monday 5 to Thursday 8 October 2009 inclusive. The meeting will be attended by one Representative of each of the Members participating in the Session, accompanied by alternates and advisers. Observers of the United Mations, the United Mations Development Programme, some of the Specialized Agencies, certain other organs of the United Mations, the League of Arab States, the African Union, and a number of other intergovernmental and nongovernmental organizations in official relations with WHO, as well as observers from some national health institutions, will also attend.

Session documents for the meeting are available in English, Arabic and French at: http://www.emro.who.int/rc56/documents.htm 